\title{
Global Eradication of Hepatitis C Virus: A Herculean Task
}

\section{Rajinder M Joshi*}

Nuclear Medicine and Laboratory Center, Yiaco Medical Co. Al Adan Hospital, Kuwait

Once dubbed under the entity of Non A-Non B (NANB) hepatitis agents, Hepatitis C Virus (HCV) was finally discovered and named in $1989[1,2] . \mathrm{HCV}$ is an enveloped single stranded positive sense $9.6 \mathrm{~kb}$ RNA virus about $50 \mathrm{~nm}$ in diameter under the hepacivirus genus within the Flaviviridae family. Approximately 200 million people (about 3\% of the world population) are currently infected with HCV including about 4 million in USA itself. The virus has 6 major genotypes and over 50 subtypes based on the genomic heterogeneity. Some experts recognize even more genotypes but it remains debatable until major genomic variability is authentically demonstrated in the new genotypes. While genotypes 1-3 have a worldwide distribution, some types are predominantly confined to certain geographical regions. Whereas type 1 is most prevalent in USA and Europe, type 3 in Southeast Asia, type 4 principally in Middle East, Egypt and Central Africa, the type 5 is almost exclusively encountered in South Africa. The prevalence rates of HCV infection vary from $<1.5 \%$ in USA to $10 \%$ or more in Egypt. For reasons largely unknown, the baby boomers (people born between 1945 to1964) account for nearly three fourths of cases in most parts of the world. The major mode of HCV transmission has been variable over time. The main determinants had been the practice of parenteral drug abuse which was uncommon before 1960 and the development of HCV screening kits for blood, tissue or organ donors which became available only in early 1990s. Though globally, the major mode of transmission has usually remained unscreened blood/tissue/organ donors, the parenteral infective drug abuse may presently be the leading mode in most parts of the world including the developed countries. The other modes of transmission include the widespread practice of tattooing, use of unsterilized injection needles, vertical transmission from mother to child and the sexual contact. The incubation period is variable but on an average it is about 8 weeks. Only $15-25 \%$ individuals are able to clear the HCV infection spontaneously. Up to $85 \%$ infections may be asymptomatic. Majority of those infected develop chronic infection which runs for decades. The symptomatic HCV infection usually presents as mild disease with jaundice in less than $50 \%$ cases in whom the liver enzymes are either slightly elevated or even within normal range. If untreated chronic liver disease, cirrhosis and hepatocellular carcinoma may develop after twenty to thirty years in majority of the cases. Co-morbidity with Hepatitis A, Hepatitis B, HIV and chronic alcoholism leads to increased mortality and also affects the treatment schedule. HCV culture in the standard cell lines has always been difficult. Given the fact that the virus undergoes frequent mutations, the precise identification of the genotype has often been questionable. Moreover, a patient may sometimes be infected with more than one genotype at the same time. Because of these above inherent limitations, the availability of reliable diagnostic kits and the development of an effective vaccine as equally the therapy for HCV infection have all been formidable challenges. Despite the various modalities of the virus culture and efforts to develop HCV vaccines using helper adenovirus and baculovirus vectors during the last over two decades, the research in this context has still to go a long journey through as the task is yet unfinished [3-7].

More recently, there has been growing enthusiasm and optimism about the global eradication of HCV. Before 2011, the standard treatment for HCV has been two-drug regime using pegylated interferon-alpha with ribavirin which produced sustained virological response (SVR) in about $40-50 \%$ for genotype I patients and upto $80 \%$ for other genotypes after 24-48 weeks therapy. Besides, the non-specific actions of interferon (injectable) and ribavirin (oral), these two drugs have their own undesirable side effects. With the FDA approval of two oral direct acting antiviral (DAA) drugs, telaprevir and boceprevir in 2011, tripledrug regime started with the addition of one of these two oral drugs to the earlier protocol. This not only improved SVR but also shortened the treatment duration. Recently simprevir and sofosbuvir, the two other oral DAA drugs which were approved by FDA in November and December 2013 respectively may be even more promising. The DAAs potentially act on the non-structural polypeptides NS2, NS3, NS4A, NS4B, NS5A and NS5B. The year 2014 heralds the beginning of new all-oral DAAs for HCV therapy which are expected to be relatively safer, more effective and with only 8 to 12 weeks treatment period. Quite a few other DAAs are presently in different clinical phase trials, some are already presented to and others are awaiting FDA approval. These include asunoprevir, danoprevir, vaniprevir, tegobuvir, filibuvir, daclatasvir, alisporivir and a host of others. In fact, a number of drug companies like Gilead Sciences Inc; Vertex Pharmaceuticals; Johnson and Johnson; Roche; Merck; Mitsubishi Tanabe Pharma; Bristol-Myers Squibb and others have actively been competing in the DAAs development. But unfortunately the HCV has already started exhibiting drug resistance to telaprevir and boceprevir, the two forerunner DAAs. However, it is premature to predict the development of the drug resistance in $\mathrm{HCV}$ against the other new DAAs. As a standard protocol, monotherapy in HCV infection is never advocated lest the drug resistance should develop. Another issue that needs to be readdressed is the warehousing (intentionally delaying treatment) of patients for HCV therapy. Especially with the more potent DAAs hitting the market soon, warehousing practice can now certainly be avoided in vast majority of patients. Unreasonable warehousing poses a great risk for HCV patients as it is difficult to predict the progress of the disease and its serious complications. Needless to mention that warehousing may not be cost effective if a patient passes on to hepatic cirrhosis, hepatocellular carcinoma or requires liver transplantation as a result of complications and intentional delay in therapy.

Global eradication of HCV is a Herculean task. So far we have been successful only in case of smallpox for its global eradication in 1980 in the real sense of the word. Driven by this grand success, other global eradication programmes for Guinea worm disease (dracunculiasis)

*Corresponding author: Rajinder M Joshi, Senior Consultant and Head Microbiology Unit; Radiology, Nuclear Medicine and Laboratory Center, Yiaco Medical Co. Al-Adan Hospital, Kuwait, Tel: 00965-66142348; E-mail: drrmjoshi2002@yahoo.com

Received February 04, 2014; Accepted February 06, 2014; Published February 10,2014

Citation: Joshi RM (2014) Global Eradication of Hepatitis C Virus: A Herculean Task. Clin Microbial 3: e118. doi:10.4172/2327-5073.1000e118

Copyright: ( 2014 Joshi RM. This is an open-access article distributed under the terms of the Creative Commons Attribution License, which permits unrestricted use, distribution, and reproduction in any medium, provided the original author and source are credited. 
and poliomyelitis were initiated in 1980 and 1988 respectively which have met with significant success, although some countries like Nigeria and Pakistan are still greatest challenges for global eradication of poliomyelitis even after 25 years of the concerted efforts. Global eradication drives for measles, malaria, yaws, plague, kala-azar and yellow fever, however, had only insignificant or partial success. Specific strategy has to be clearly defined for any eradication programme which varies with the targeted disease agent. At times there may be resurgence of a targeted disease which may even stage comeback with a vengeance. Concerted global efforts, education, awareness, local low cost diagnostic kits and antiviral drugs development with their availability and regular distribution, administrative and political will/commitment, active participation of both government and non-government organizations, good antenatal care, safe and protected sexual practices, control and check on the reuse of injection syringesare the critical issues to be addressed in the specific strategy for global eradication of HCV. Strict legislation/laws and their enforcement for mandatory HCV screening of blood/tissue donors especially in the developing countries should be ensured. Parenteral drug abuse, a big global monster particularly in the young adults is really a hard nut to crack.

HCV has a limited host range. The infection is confined only to humans, though chimpanzees can be experimentally infected. The limited host range and the availability of effective DAAs are the favorable factors for eradication of $\mathrm{HCV}$ in majority of patients. The problems of culture of HCV in cell lines, the existence of multiple genotypes, subtypes, non- availability of an effective and potent vaccine, genetic variations and drug resistance and cross resistance are the major limitations in the global eradication of HCV. However, it is expected that with the availability of DAAs, the global HCV prevalence will substantially decrease in coming years. It may though be possible to control or even eliminate $\mathrm{HCV}$ in certain geographical regions of the world, unless an effective pan-genotype HCV vaccine becomes available at an affordable price particularly for the developing world, the global eradication of $\mathrm{HCV}$ is a distant prospect and probably decades away.

\section{References}

1. Choo QL, Kuo G, Weiner AJ, Overby LR, Bradley DW, et al. (1989) Isolation of a cDNA clone derived from a blood-borne non-A, non-B viral hepatitis genome. Science 244: 359-362.

2. Kuo G, Choo QL, Alter HJ, Gitnick GL, Redeker AG, et al. (1989) An assay for circulating antibodies to a major etiologic virus of human non-A, non-B hepatitis. Science 244: 362-364.

3. Zhou X, Zeng Y, Li J, Guo Y, Fu Y, et al. (2013) A novel helper-dependent adenovirus-based cell culture model for Hepatitis $\mathrm{C}$ virus replication and production. Virol J 10: 273.

4. Belyaev AS, Hails RS, Roy P (1995) High-level expression of five foreign genes by a single recombinant baculovirus. Gene 156: 229-233.

5. Futatsumori-Sugai M, Tsumoto K (2010) Signal peptide design for improving recombinant protein secretion in the baculovirus expression vector system. BiochemBiophys Res Commun 391: 931-935.

6. Matsuo E, Tani H, Lim Ck, Komoda Y, Okamoto T, et al. (2006) Characterization of HCV-like particles produced in a human hepatoma cell line by a recombinant baculovirus. BiochemBiophys Res Commun 340: 200-208.

7. Palomares LA, Mena JA, Ramírez OT (2012) Simultaneous expression of recombinant proteins in the insect cell-baculovirus system: production of viruslike particles. Methods 56: 389-395 